\title{
The Welfare Cost of Business Cycles in an Economy with Nonclearing Markets
}

\author{
Franck Portier and Luis A. Puch*†‡
}

March 2004

\begin{abstract}
In this paper we measure the welfare cost of fluctuations in a simple representative agent economy with nonclearing markets. The market friction we consider involves price rigidities and a voluntary exchange rationing scheme. These features are incorporated into an otherwise standard neoclassical growth model. We show that the frictions we introduce make the losses from fluctuations much bigger than in a frictionless environment.
\end{abstract}

Keywords: Cost of Business Cycles - Nonclearing Markets - Dynamic General Equilibrium

JEL code: E32, C63, C68

* Respectively Université de Toulouse and, Universidad Complutense de Madrid and ICAE.

${ }^{\dagger}$ Corresponding author: Franck Portier, Batiment F, Manufacture des Tabacs, Université des Sciences Sociales, 21 Allée de Brienne, F-31000 Toulouse, France. Tel: +33 (0)5 611288 40, Fax: +33 (0)5 6112 86 37, e-mail: fportier@cict.fr. Portier is affiliated to LEERNA, GREMAQ, IDEI, Institut Universitaire de France and CEPR.

${ }^{\ddagger}$ We thank J. Adda, P. Beaudry, J.P. Bénassy, F. Collard, J. Durán, J.F. Fagnart, P. Fève, S. Grégoir, P.Y. Hénin, T. Kehoe, F. Langot, O. Licandro and V. Ríos-Rull for helpful comments and suggestions. We are also grateful to the editor and two anonymous referees. Puch thanks DGCYT (projects PB98-0831 and SEC00-0269), FEDEA and Fundación Ramón Areces. 


\section{Introduction}

In a seminal contribution, Lucas [1987] has shown that in a representative agent framework, the potential welfare gain from stabilizing consumption around its mean is small. Let us recall briefly Lucas's argument. Assume that aggregate consumption follows a log linear process around a deterministic trend, $c_{t}=(1+\mu)^{t} e^{-\frac{1}{2} \sigma_{z}^{2}} z_{t}$, where $\left\{z_{t}\right\}$ is a stationary stochastic process with a stationary distribution given by $\ln z_{t} \rightsquigarrow N\left(0, \sigma_{z}^{2}\right)$ so the expected value of consumption does not depend on the variance. Then, the cost of instability can be computed as the percentage increase in consumption, uniform across all dates and values of the shocks, required to leave the consumer indifferent between consumption instability and a perfectly smooth consumption path. With a CRRA utility function with risk aversion coefficient $\nu$, this cost is given by $\frac{1}{2} \nu \sigma_{z}^{2}$. With $\sigma_{z}=0.013$ (Lucas's estimate), and $\nu=5$, the welfare cost of fluctuations is only $0.042 \%$ of average consumption. When implemented in calibrated versions of standard representative-agent Dynamic Stochastic General Equilibrium (DSGE) models, the conclusion is basically unchanged 1

In this paper we propose a model in which the welfare cost of fluctuations is non trivial, because fluctuations magnify some market imperfections. The market friction we consider is the predetermination of some prices. When prices are set in advance, markets do not clear, and we assume that transactions occur at the minimum of demand and supply. Such a rationing scheme is known as "voluntary exchange hypothesis" in the literature on nonclearing

\footnotetext{
${ }^{1}$ Two strands of the literature have looked for DSGE models in which Lucas's measure can be higher. The first relaxes the assumption of a representative agent and introduces incomplete insurance markets as in Imrohoroglu [1988], Atkeson and Phelan [1994] and Krusell and Smith [1999] among others. A second strand, following the work of Epstein and Zin [1991], adopts more general utility functions, for which the intertemporal elasticity of substitution is not the inverse of the degree of relative risk aversion, as in Obstfeld [1994] and Epaulard and Pommeret [2003] among others.
} 
markets (see Benassy [1993] for an overview), and it is a very natural one in a free market economy: no agent can be forced to purchase more than she demands, or to sell more than she supplies. As in Lucas [1987] and Lucas [203], our approach consists of measuring the costs to risk averse households of the consumption variability associated with the business cycle $2^{2}$ As we know the model economy we adopt a structural measure of the welfare cost of fluctuations. We discuss this measure and its relation with a measure that only requires the knowledge of the equilibrium process of consumption in some detail.

We show that nonclearing markets make the losses from fluctuations much bigger than in a frictionless environment. But this is so only when the welfare cost of fluctuations is measured taking fully account of transitions and nonlinearities. In order to make the argument more transparent we restrict ourselves to a fully analytically computable case.

The paper is organized as follows. In Section 2 we present a simple analytical Real Business Cycle model with or without nonclearing markets. Section 3 describes the way we measure welfare costs of fluctuations. In Section 4 we present our main quantitative results. A last section concludes.

\section{The Model Economy}

We first introduce the environment, and then describe the two cases we consider: the walrasian case and the nonclearing market case.

The economy is competitive, populated by one final good firm, one intermediate good firm and one household. All agents behave competitively and have rational expectations.

\footnotetext{
${ }^{2} \mathrm{As}$ it is standard in this context we are restricting ourselves to the question about the welfare gains of eliminating business cycles which is truly a hypothetical one. The limitation of doing so is that the exercise is silent about the design of policy that would stabilize the economy.
} 
The final good is the numéraire. The household buys the consumption good, accumulates capital, and sells labor services to the intermediate good firm at price $w_{t}$ and capital services to the final good firm at price $z_{t}$. The intermediate good firm uses only labor as input, and sells its output to the final good firm at price $\omega_{t}$. The final good firm sells its output to the household, that allocates it between consumption $c_{t}$ and investment (next period capital) $k_{t}$. The production function of the final good firm is subject to technology shocks. The intermediate and consumption good cannot be stored.

The non-walrasian feature of the model comes from the fact that the price of the intermediate good is set, before observation of the technology shock, at the level that clears the intermediate good market in expectation (the expected walrasian price). As there are no pricing decisions made by agents in this competitive model, the next period walrasian price is a natural target for price setting. Such an assumption is generally made in the fixed-price literature with perfect competition (see for example Benassy [1995]). The production of the intermediate good is done before observation of the technology shock, and the worker is promised a wage that is indexed on the firm sales. The payment of that wage is done after observation of the shock and transactions on the intermediate good market. Therefore, in case of a negative surprise on the level of technology, a fraction of the intermediate good will not be sold, and will be wasted, although the amount wasted is zero in expectations. Once the shock is observed, the final good firm determines its optimal demand for intermediate good, and trade occurs. As prices are not walrasian, supply and demand will not equalize, and a rationing scheme must be specified. We assume voluntary exchange: no agent is forced to buy or sell if she does not want to. As a consequence, the level of transaction on the intermediate good market will be the minimum of demand and supply at given (non walrasian) 
price. If demand is lower than supply, workers will receive a wage that is ex post lower than their marginal disutility of labor, although it was ex ante clearing the labor market. Without shocks, the preset price economy replicates the competitive allocations, and is therefore efficient. Fluctuations are costly not only because agents prefer smooth consumption and leisure, as in the competitive model, but also because fluctuations create inefficiencies and a waste of resources.

It goes without saying that the calibrated model we consider needs not to be the most realistic, as we restrict ourselves to a fully analytically computable case. Indeed, we will consider a case with logarithmic utility, lognormal shocks and full depreciation.

\subsection{Technology and Preferences}

Utility is derived from consumption and leisure, the intermediate good is produced with labor, while the final good is produced using capital and the intermediate good. The final good is either consumed or invested.

More specifically, the final good firm uses $h_{t}$ units of the intermediate good and $k_{t}$ units of capital to produce according to a Cobb Douglas technology:

$$
y_{t}=\theta_{t} k_{t-1}^{\alpha} h_{t}^{1-\alpha}
$$

with

$$
\theta_{t}=\Theta\left(\sigma_{\varepsilon}, \rho\right) \theta_{t-1}^{\rho} \varepsilon_{t}
$$

Here, $\varepsilon_{t}$ is the innovation to $\theta_{t}$, and it is assumed that $\log \varepsilon_{t}$ follows an i.i.d. Gaussian process with zero mean and standard deviation $\sigma_{\epsilon}$. We also assume that $|\rho|<1$. $\Theta\left(\sigma_{\varepsilon}, \rho\right)=$

$\left(\exp \left(-\frac{1}{2} \frac{\sigma_{\varepsilon}^{2}}{1-\rho^{2}}\right)\right)^{1-\rho}$ is a correction parameter that guarantees that the mean of $\theta$ is always 
equal to one, for any level of $\sigma_{\varepsilon}$ and $\rho$. Therefore, variations in the level of $\sigma_{\varepsilon}$ will be mean preserving spread variations of uncertainty. It is useful for the following to note that $\theta_{t}=E_{t-1}\left[\theta_{t}\right] \varepsilon_{t}$.

The final good cannot be stored, is used for consumption and investment, and capital fully depreciates from one period to another, so that

$$
c_{t}+k_{t}=y_{t}
$$

The intermediate good firm hires labor $n_{t}$ and produces intermediate good $h_{t}$ according to the linear one-to-one technology

$$
h_{t}=n_{t}
$$

The intermediate good cannot be stored.

Preferences are given by the following expected discounted lifetime utility

$$
E_{t}\left[\sum_{j=0}^{\infty} \beta^{j}\left(\log c_{t+j}+\gamma \log \left(1-n_{t+j}\right)\right)\right]
$$

We consider two cases. In the first one (the Walrasian case), there are no preset prices. In the second case (the nonclearing markets case), the price $\omega_{t}$ of the intermediate good is preset and the production of the intermediate good is realized before the current shock has been observed.

\subsection{The Walrasian Case}

In this case, all decisions are taken after the shock $\varepsilon_{t}$ has been revealed.

Optimal Individual Behavior : The final good firm maximizes its profit $y_{t}-\omega_{t} h_{t}-z_{t} k_{t-1}$

for given walrasian input prices $\omega_{t}$ (labor) and $z_{t}$ (capital). From this problem, one gets the 
two following first order conditions:

$$
\begin{aligned}
\omega_{t} & =(1-\alpha) \theta_{t} k_{t-1}^{\alpha} h_{t}^{-\alpha} \\
z_{t} & =\alpha \theta_{t} k_{t-1}^{\alpha-1} h_{t}^{1-\alpha}
\end{aligned}
$$

The household maximizes its utility with respect to an intertemporal budget constraint. This problem admits the following recursive representation:

$$
\begin{gathered}
V\left(k_{t-1}, \theta_{t}\right)=\max _{c_{t}, n_{t}, k_{t+1}}\left\{\left(\log c_{t}+\gamma \log \left(1-n_{t}\right)\right)+\beta E_{t} V\left(k_{t}, \theta_{t+1}\right)\right\} \\
\text { s.t. } \quad c_{t}+k_{t} \leq z_{t} k_{t-1}+w_{t} n_{t}
\end{gathered}
$$

The first order conditions of this problem are given by

$$
\begin{aligned}
\frac{\gamma}{1-n_{t}} & =\frac{w_{t}}{c_{t}} \\
\frac{1}{c_{t}} & =\beta E_{t}\left[\frac{z_{t+1}}{c_{t+1}}\right]
\end{aligned}
$$

together with the budget constraint and the transversality condition $\lim _{j \rightarrow \infty} E_{t} \beta^{j} \frac{k_{t+j}}{c_{t+j}}=0$.

The intermediate good firm maximizes $\omega_{t} h_{t}-w_{t} n_{t}$ subject to the technological constraint $h_{t} \leq n_{t}$. Its optimal behavior is therefore

$$
\begin{cases}n_{t}=h_{t}=0 & \text { if } w_{t}>\omega_{t} \\ n_{t}=h_{t} \geq \quad 0 & \text { if } w_{t}=\omega_{t} \\ n_{t}=h_{t}= & \text { if } w_{t}<\omega_{t}\end{cases}
$$

Walrasian Equilibrium : From those optimal behaviors, and imposing market clearing conditions on the input and product markets, one can derive equilibrium allocations and prices. From the intermediate good firm behavior (12), we have that, at the walrasian equilibrium, $\omega_{t}=w_{t}$ and $h_{t}=n_{t} \forall t$, so that the intermediate good firm is transparent. From (11) and (7), and using (3), we obtain

$$
\frac{k_{t}}{c_{t}}=\alpha \beta E_{t}\left[1+\frac{k_{t+1}}{c_{t+1}}\right]
$$


Solving (13) forward, using (3) and the transversality condition, we obtain

$$
\begin{aligned}
c_{t} & =(1-\alpha \beta) y_{t} \\
k_{t} & =\alpha \beta y_{t}
\end{aligned}
$$

In this model, the saving rate is constant, which is key to get an analytical solution. Combining (10) with (6) and (14) gives

$$
h_{t}=\widetilde{h}=n_{t}=\widetilde{n}=\frac{(1-\alpha)}{1-\alpha+\gamma(1-\alpha \beta)}
$$

According to (16), employment is constant in a competitive equilibrium.

In the walrasian case, the dynamics is therefore fully characterized by the following set of equations:

$$
\left\{\begin{aligned}
h_{t} & =\widetilde{h} \\
n_{t} & =h_{t} \\
\theta_{t} & =\Theta\left(\sigma_{\varepsilon}, \rho\right) \theta_{t-1}^{\rho} \varepsilon_{t} \\
y_{t} & =\theta_{t} k_{t-1}^{\alpha} h_{t}^{1-\alpha} \\
c_{t} & =(1-\alpha \beta) y_{t} \\
k_{t} & =\alpha \beta y_{t} \\
w_{t}^{w} & =(1-\alpha) \theta_{t} k_{t-1}^{\alpha} h_{t}^{-\alpha}
\end{aligned}\right.
$$

where the superscript $w$ stands for walrasian. Note that one will have $\omega_{t}^{w}=w_{t}^{w}$

\subsection{The Nonclearing Market Case}

In that case, we assume that the period is composed of two subperiods. In the first one, the shock $\varepsilon_{t}$ is unknown, while it is known on the second.

First Subperiod Optimal Individual Behavior : In that subperiod, the household supplies labor to the intermediate good firm, production of intermediate good takes place and the price $\omega_{t}$ at which the intermediate good will be sold to the final good firm is set. 
The household's labor supply and optimal consumption-saving behavior follows from the program

$$
\begin{gathered}
V\left(k_{t-1}, \theta_{t-1}\right)=\max _{n_{t}}\left\{\gamma \log \left(1-n_{t}\right)+E_{t-1}\left[\max _{k_{t}, c_{t}}\left\{\log c_{t}+\beta E_{t} V\left(k_{t}, \theta_{t}\right)\right\}\right]\right\} \\
\text { s.t. } \quad c_{t}+k_{t} \leq z_{t} k_{t-1}+w_{t} n_{t}
\end{gathered}
$$

Note that labor supply is decided before observation of the shock while consumption and savings are decided after. The first order conditions of this problem are given by

$$
\begin{aligned}
\frac{\gamma}{1-n_{t}} & =E_{t-1}\left[\frac{w_{t}}{c_{t}}\right] \\
\frac{1}{c_{t}} & =\beta E_{t}\left[\frac{z_{t+1}}{c_{t+1}}\right]
\end{aligned}
$$

together with the budget constraint and the transversality condition $\lim _{j \rightarrow \infty} E_{t} \beta^{j} \frac{k_{t+j}}{c_{t+j}}=0$.

The intermediate firm maximizes its expected profit $E_{t-1}\left[\omega_{t} h_{t}-w_{t} n_{t}\right]$, and follows the following optimal rule:

$$
\left\{\begin{array}{ccc}
n_{t}= & 0 & \text { if } E_{t-1}\left[w_{t}\right]<\omega_{t} \\
n_{t}= & E_{t-1}\left[h_{t}\right] \geq 0 & \text { if } E_{t-1}\left[w_{t}\right]=\omega_{t} \\
n_{t}= & \infty & \text { if } E_{t-1}\left[w_{t}\right]>\omega_{t}
\end{array}\right.
$$

It is assumed that $\omega_{t}$ is preset at the level that clears the intermediate good market at period $t$ in expectation $E_{t-1}\left[\omega_{t}^{w}\right]=E_{t-1}\left[w_{t}^{w}\right]$. We therefore have

$$
\omega_{t}=E_{t-1}\left[\omega_{t}^{w}\right]=E_{t-1}\left[w_{t}^{w}\right]=(1-\alpha) k_{t-1}^{\alpha} \widetilde{n}^{-\alpha} E_{t-1}\left[\theta_{t}\right]
$$

where we use the fact that $k_{t}$ is known at period $t-1$.

As the amount of sales of the intermediate good firm in the second subperiod is uncertain, the wage contract it offered to the household is specified as follows. The household works $n_{t}$ in subperiod 1, and receives in subperiod 2 the proceeds of the intermediate goods $\omega_{t}^{w} h_{t}$. The 
current wage offered is therefore $w_{t}=E_{t-1}\left[\omega_{t} h_{t}\right] / n_{t}$. Note that profits of the intermediate good firm are null in all states of the world $!^{3}$

Second subperiod Optimal Individual Behavior : In the second subperiod, the shock $\varepsilon_{t}$ is revealed, and the final firm determines its optimal demands for input, that solve

$$
\begin{aligned}
\omega_{t} & =(1-\alpha) \theta_{t} k_{t-1}^{\alpha} h_{t}^{-\alpha} \\
z_{t} & =\alpha \theta_{t} k_{t-1}^{\alpha-1} h_{t}^{1-\alpha}
\end{aligned}
$$

In particular, intermediate input demand is given by (solving (24) for $h_{t}$ ):

$$
h_{t}^{d}=\omega_{t}^{-1 / \alpha}(1-\alpha)^{1 / \alpha} \theta_{t}^{1 / \alpha} k_{t-1}
$$

The intermediate firm holds a stock of intermediate good $h_{t}^{s}=n_{t}$, that has been produced in subperiod 1, and sells as much as it can for the preset price $\omega_{t}$. Transactions on the intermediate good market will be given by $h_{t}=\min \left(h_{t}^{s}, h_{t}^{d}\right)$

The household receives labor income $\omega_{t} h_{t} / n_{t}$, and decides to allocate it between consumption and investment according to (21) together with the budget constraint and the transversality condition.

Nonclearing Market Equilibrium : We first derive the optimal non walrasian equilibrium employment, and then compute other equilibrium quantities. From the expression of intermediate input demand $(26)$ and the value of the $w_{t}$, as given in $(23)$, we get

$$
h_{t}^{d}=\widetilde{n} \varepsilon_{t}^{1 / \alpha}
$$

\footnotetext{
${ }^{3}$ An alternative interpretation can be given to the wage schedule. One can assume that the intermediate firms promise a fixed wage $w_{t}^{w}$ to the worker. If $\varepsilon_{t}>1$, then the intermediate firm sells all its output and is able to pay its wage bill. If $\varepsilon_{t}<1$, then cash flow $\omega_{t} h_{t}$ is smaller than the wage bill. The firm goes bankrupt and the worker, who is the only claimant, gets the residual value of the firm $\omega_{t} h_{t}$, which is $\omega_{t} h_{t} / n_{t}$ per unit of time worked.
} 
where $\widetilde{n}$ is the constant walrasian equilibrium level of employment and intermediate input production in the walrasian equilibrium. From the optimal behavior of the intermediate firm (22), we obtain that in a nonclearing market equilibrium, $n_{t}=E_{t-1}\left[h_{t}\right]$ and $\omega_{t}=E_{t-1}\left[w_{t}\right]$. Therefore,

$$
h=\min \left(n_{t}, \tilde{n} \varepsilon_{t}^{1 / \alpha}\right)
$$

Using (25), (21), the budget constraint and the transversality condition, we obtain that the saving rate is also constant in the nonclearing market economy:

$$
\begin{aligned}
c_{t} & =(1-\alpha \beta) y_{t} \\
k_{t} & =\alpha \beta y_{t}
\end{aligned}
$$

One can now compute the right hand side of labor supply (20), using (23), (28) and (29):

$$
E_{t-1}\left[\frac{w_{t}}{c_{t}}\right]=\frac{1-\alpha}{1-\alpha \beta} \frac{\widetilde{n}^{-\alpha}}{n_{t}} E_{t-1}\left[\left(\min \left(n_{t}, \widetilde{n} \varepsilon_{t}^{1 / \alpha}\right)^{\alpha}\right]\right.
$$

Optimal first subperiod labor supply is therefore the solution of

$$
\frac{\gamma n_{t}}{(1-\alpha)\left(1-n_{t}\right)}=\frac{1}{1-\alpha \beta} \widetilde{n}^{-\alpha} E_{t-1}\left[\frac{\left(\min \left(n_{t}, \widetilde{n} \varepsilon_{t}^{1 / \alpha}\right)^{\alpha}\right.}{\varepsilon_{t}}\right]
$$

Equation 32 deserves some comments. First, the solution does not depend on time, as $\varepsilon$ is an iid shock. Therefore, we will have $n_{t}=\bar{n} \forall t$ in the nonclearing market equilibrium. Second, without shocks, i.e. if $\varepsilon_{t}=1 \forall t$, the preset price $\omega_{t}$ is the walrasian one, and one can check that $\bar{n}=\widetilde{n}$. Third, $\bar{n}<\widetilde{n}$ : as there exists some uncertainty on the second subperiod wage when the household supplies hours, a precautionary motive leads to lower labor supply and lower employment. Equation (32) has no analytical solution, but its solution can be easily computed numerically. Once $\bar{n}$ is known, the rest of the model is solved trivially. 
In the nonclearing markets case, the dynamics of aggregate quantities is therefore fully characterized by the following set of equations:

$$
\left\{\begin{aligned}
n_{t} & =\bar{n} \\
\theta_{t} & =\Theta\left(\sigma_{\varepsilon}, \rho\right) \theta_{t-1}^{\rho} \varepsilon_{t} \\
h & =\min \left(n_{t}, \widetilde{n} \varepsilon_{t}^{1 / \alpha}\right) \\
y_{t} & =\theta_{t} k_{t-1}^{\alpha} h_{t}^{1-\alpha} \\
c_{t} & =(1-\alpha \beta) y_{t} \\
k_{t} & =\alpha \beta y_{t}
\end{aligned}\right.
$$

\section{$3 \quad$ Welfare Analysis}

\subsection{Measuring Costs}

To obtain a structural (model driven) measure of the welfare cost of fluctuations, we compare the economies with and without fluctuations starting from the same set of initial conditions $S=(k, \theta)$. The measure we compute can be understood as the outcome of the following thought experiment of structural change: let us assume that we have been in an economy with shocks from $-\infty$ to $T-1$, and that from $T$ to $\infty$, fluctuations are eliminated by setting $\varepsilon_{t}=1 \forall t \geq T$. We evaluate the welfare gain of this structural change by comparing the expected intertemporal utility of the representative agent in two economies: an economy $A$ that starts with initial condition $S_{T-1}$ and in which shocks are not shut down; an economy $B$ that starts with initial condition $S_{T-1}$ and without shocks. The conditional (on $S_{T-1}$ ) welfare cost of fluctuations $\mathcal{C}\left(S_{T-1}\right)$ is then defined as the percentage increase in consumption, uniform across all dates and values of the shocks, required to leave the consumer indifferent between consumption path $A$ and $B$. By repeating this experiment for many different starting points, drawn in the ergodic distribution of the economy with shocks, one will get an unconditional measure of the welfare cost of fluctuations $\mathcal{C}=E\left[\mathcal{C}\left(S_{T-1}\right)\right]$. More formally, the measure we propose is given by 


$$
\begin{aligned}
& \int_{S_{T-1}} \int_{\mathcal{E}} \sum_{j=0}^{\infty} \beta^{j}\left[\log \left(c_{T+j}^{A}\left(1+\mathcal{C} \times c_{S S}\right)\right)+\gamma \log \left(1-n_{T+j}^{A}\right)\right] \mathrm{d} g(\mathcal{E}) \mathrm{d} f(S) \\
& =\int_{S_{T-1}} \sum_{j=0}^{\infty} \beta^{j}\left[\log c_{T+j}^{B}+\gamma \log \left(1-n_{T+j}^{B}\right)\right] \mathrm{d} f(S) .
\end{aligned}
$$

where $\mathcal{E}$ is an infinite sequence of $\varepsilon$ and $f$ the ergodic joint density of $(k, \theta)$ in the economy with shocks. Note that $\mathcal{C}$ is expressed in percentage points of the non stochastic steady-state level of consumption $c_{S S}$. Next we explain the way in which we implement the unconditional measure of the welfare cost of fluctuations that we refer to as a comprehensive one.

\subsection{Computation of the Welfare Cost of Fluctuations}

The first step consists of computing the solution of the model. This is immediate in our simple analytical case but it should be obtained by accurate computational methods in most DSGE models. Note that even though we are able to obtain an analytical solution to the model in the nonclearing market case, we cannot compute its moments analytically, because of its nonlinearity (the min operator). We then simulate the solution of the model over 45.000 periods and build upon an empirical estimate of the invariant distribution $f(k, \theta)$ of capital stock and productivity to obtain an evenly spaced grid of $50 \times 50$ points in the $k \times \theta$ space. Then we draw initial conditions $\left(k_{-1}, \theta_{-1}\right)$ in that probability distribution of the economy with shocks to compute a 1500 periods deterministic transition to the non stochastic steady state 4 These paths are denoted $\left\{c_{k_{-1}, \theta_{-1}}^{B}(t), n_{k_{-1}, \theta_{-1}}^{B}(t)\right\}_{t=0}^{1499}$.

We proceed in a similar way for the economy with shocks. Specifically, this amounts to simulating 1000 stochastic paths starting from the same initial conditions from which no-

\footnotetext{
${ }^{4}$ We extensively compute transition paths for all the cells of the 50 by $50(k, \theta)$ matrix, and then weight the utility of each of these paths with the density of its initial conditions.
} 
uncertainty transition paths have been computed. These paths are denoted correspondingly $\left\{c_{k_{-1}, \theta_{-1}}^{A}(t), n_{k_{-1}, \theta_{-1}}^{A}(t)\right\}_{t=0}^{1499}$.

We then evaluate $\mathcal{C}$, our comprehensive measure, using equation (34). We also compute the measure $\ell=\frac{1}{2} \sigma_{z}^{2}$ that corresponds to a non structural evaluation, with $\sigma_{z}^{2}=$ $E\left[\left(c^{A}-E\left(c^{A}\right)\right)^{2}\right]$.

\section{Quantitative Findings}

The choice of parameter values used in the simulation of the model is given in Table 1. All these values are standard in the literature. Note that we assume full depreciation to obtain an analytical solution. The disutility of labor parameter $\gamma$ is set such that worked hours represent $20 \%$ of the time endowment at the non stochastic steady state.

\section{Table 1: Parameters}

\begin{tabular}{lll}
\hline \hline Preferences & & \\
Subjective discount factor & $\beta$ & 0.99 \\
$\begin{array}{l}\text { Disutility of labor } \\
\text { Technology }\end{array}$ & $\gamma$ & 3.9712 \\
Capital elasticity & $\alpha$ & 0.42 \\
$\begin{array}{l}\text { Depreciation rate } \\
\text { Shock process }\end{array}$ & $\delta$ & 1 \\
Serial Correlation of Tech. shock & $\rho$ & 0.95 \\
Std. dev. of innovation & $\sigma$ & 0.01 \\
\hline \hline
\end{tabular}

Table 2: Welfare Cost of Fluctuations

\begin{tabular}{lcc}
\hline \hline & $\ell$ & $\mathcal{C}$ \\
Walrasian economy & $0.14 \%$ & $0.14 \%$ \\
Nonclearing markets & $0.16 \%$ & $0.66 \%$ \\
\hline \hline
\end{tabular}

Table 2 reports the welfare results. First, notice that in the walrasian case, the comprehensive welfare cost of fluctuations $\mathcal{C}$ is small, and equal to the non structural measure 
$\ell$. This result holds because the model is log-linear and shocks are log-normal. Second, the introduction of price rigidities sharply modifies the evaluation of the welfare cost of fluctuations, as $\mathcal{C}$ is now five time bigger. With low risk aversion and small shocks $\left(\sigma_{\varepsilon}=0.01\right)$, we measure the welfare cost of fluctuations to be about $0.66 \%$ of deterministic steady state consumption. In the nonclearing market economy, the dominant effects are the underutilization of labor and the waste of intermediate goods. In every period, worked hours are lower than what they would have been had the real wage been flexible. Therefore, capital is less productive, accumulation is lower, and output and consumption are lower than in a walrasian economy. On top of that, there is a waste of intermediate goods when productivity is lower than expected, as the final good firm does not buy all the production at the preset price. Once shocks are shut down, the allocation of the preset price economy coincides with the flexible economy one: the value of capital increases given that time is now efficiently allocated between work and leisure, and no intermediate goods are wasted. Therefore, the welfare cost of fluctuations is large. This cost is not properly measured by the non structural measure $\ell$, as this measure does not take into account the increase in the mean of consumption that is associated with stabilization. The $\mathcal{C}$ measure, taking into account nonlinearities (the "min" function in this simple model) and computing the transition from the stochastic steady-state to the deterministic one, gives a comprehensive measure of this cost.

\section{Concluding remarks}

When a structural measure of the welfare cost of fluctuations is adopted, this cost appears to be non trivial in economies where allocations are inefficient, and where those inefficiencies are magnified by shocks. In the (admittedly specific) example of this paper, the comprehensive 
measure can be almost one order of magnitude larger than in a walrasian model. Working out the value of the comprehensive measure in more realistic environments is a potentially fruitful route, that we leave for further research.

\section{References}

Atkeson, A., And C. Phelan (1994): "Reconsidering the costs of business cycles with incomplete markets," in NBER Macroeconomics Annual, ed. by S. Fischer, and J. Rotemberg, pp. 187-207. MIT Press.

Benassy, J. (1993): "Nonclearing Markets: Microeconomic Concepts and Macroeconomic Applications," Journal of Economic Literature, 31(2), 732-761.

(1995): "Money and wages contracts in an optimizing model of the business cycle," Journal of Monetary Economics, 35(2), 303-15,.

Epaulard, A., And A. Pommeret (2003): "Recursive utility, endogenous growth, and the welfare cost of volatility," Review of Economic Dynamics, 6(3), 672-684.

Epstein, L., And S. ZIN (1991): "Substitution, risk aversion and the temporal behavior of consumption and asset returns: an empirical analysis," Journal of Political Economy, $99(2), 261-86$.

Imrohoroglu, A. (1988): "Cost of business cycle with indivisibilities and liquidity constraints," Journal of Political Economy, 97, 1664-83.

Krusell, P., And A. Smith (1999): "On the Welfare Effects of Eliminating Business Cycles," Review of Economic Dynamics, 2(1), 245-272. 
LuCAS, R. (1987): Models of Business Cycles. Basil Blackwell, Oxford. (203): "Macroeconomic Priorities," mimeo, University of Chicago, AEA 2003 Presidential Address.

Obstfeld, M. (1994): "Evaluating risky consumption paths: the role of intertemporal substituability," European Economic Review, 38, 1471-86. 